University of Nebraska - Lincoln

DigitalCommons@University of Nebraska - Lincoln

U.S. Environmental Protection Agency Papers

U.S. Environmental Protection Agency

2009

The development and inter-laboratory verification of LC-MS

libraries for organic chemicals of environmental concern

Charlita Rosal

U.S. EPA

Don Betowski

U.S. EPA

Joe Romano

Waters Corporation

Joshua Neukom

U.S. EPA

Dennis Wesolowski

U.S. EPA

See next page for additional authors

Follow this and additional works at: https://digitalcommons.unl.edu/usepapapers

Rosal, Charlita; Betowski, Don; Romano, Joe; Neukom, Joshua; Wesolowski, Dennis; and Zintek, Lawrence, "The development and inter-laboratory verification of LC-MS libraries for organic chemicals of environmental concern" (2009). U.S. Environmental Protection Agency Papers. 176.

https://digitalcommons.unl.edu/usepapapers/176

This Article is brought to you for free and open access by the U.S. Environmental Protection Agency at DigitalCommons@University of Nebraska - Lincoln. It has been accepted for inclusion in U.S. Environmental Protection Agency Papers by an authorized administrator of DigitalCommons@University of Nebraska - Lincoln. 


\section{Authors}

Charlita Rosal, Don Betowski, Joe Romano, Joshua Neukom, Dennis Wesolowski, and Lawrence Zintek 


\title{
The development and inter-laboratory verification of LC-MS libraries for organic chemicals of environmental concern ${ }^{\text {is }}$
}

\author{
Charlita Rosal ${ }^{\mathrm{a}}$, Don Betowski ${ }^{\mathrm{a}}$, Joe Romano ${ }^{\mathrm{b}}$, Joshua Neukom ${ }^{\mathrm{c}}$, \\ Dennis Wesolowski ${ }^{\mathrm{c}}$, Lawrence Zintek ${ }^{\mathrm{c}, *}$ \\ a US EPA Office of Research and Development/National Exposure Research Laboratory-Environmental Sciences Division, Las Vegas, NV 89119, United States \\ ${ }^{\mathrm{b}}$ Waters Corporation, Milford, MA 01757, United States \\ c US EPA Region 5 Chicago Regional Laboratory, Chicago, IL 60605, United States
}

\section{A R T I C L E I N F O}

\section{Article history:}

Received 7 January 2009

Received in revised form 4 May 2009

Accepted 6 May 2009

Available online 15 May 2009

\section{Keywords:}

Liquid chromatography-mass spectrometry

Library

Verification

Transferability

Drinking water

\begin{abstract}
A B S T R A C T
The development, verification, and comparison study between LC-MS libraries for two manufacturers' instruments and a verified protocol are discussed. Compounds in the libraries are among those considered by the U.S. EPA Office of Water as threats to drinking water including pesticides, drugs of abuse, and pharmaceuticals. The LC-MS library protocol was verified through an inter-laboratory study that involved Federal, State, and private laboratories. The results demonstrated that the libraries are transferable between the same manufacturer's product line, and have applicability between manufacturers. Although ion abundance ratios within mass spectra were shown to be different between the manufacturers' instruments, the NIST search engine match probability was at 96\% or greater for 64 out of 67 compounds evaluated.
\end{abstract}

Published by Elsevier B.V.

\section{Introduction}

Gas chromatography coupled with mass spectrometry (GC-MS) is one of the best techniques for identifying unknown compounds in environmental samples. A major reason for its utility is the searchable libraries of mass spectra that have been compiled using electron impact ionization. These libraries are essentially instrument independent, so whichever brand of GC-MS is used, a compound can theoretically be tentatively identified, if it is included in the mass spectral libraries. This is made possible by the use of standard 70-eV electron impact ionization using a standardized tuning procedure as described elsewhere [1]. Libraries of mass spectra, such as the NIST [2] library, have automatic searching routines which list the top possibilities.

The more recently introduced liquid chromatography-mass spectrometry (LC-MS) has advantages over GC-MS for organic

\footnotetext{
th Notice: The U.S. Environmental Protection Agency (EPA) through its Office of Research and Development (ORD), collaborated in the research described here with EPA Region 5 Chicago Regional Laboratory and Waters Corporation. This manuscript has been subjected to the EPA's peer and administrative review and has been approved for publication. Mention of trade names or commercial products does not constitute endorsement or recommendation by EPA for use.

* Corresponding author. Tel.: +1 312886 2925; fax: +1 3128862591.

E-mail address: zintek.lawrence@epa.gov (L. Zintek).
}

compounds that are thermally labile, polar, or non-volatile. Derivatization of polar analytes and solvent extraction of drinking water are not required prior to analysis, both of which greatly increase the analysis time. Water samples can be analyzed directly after filtration through a syringe-driven disposable filter to remove debris that can clog the LC injector, tubing, or column.

Additionally, highly-polar or low-volatility organic compounds do not traverse GC columns or do so over such a long time that discrete gas chromatographic peaks may not be observed. Thermally unstable compounds are often degraded in the GC inlet or later in a hot GC column. HPLC separations are generally accomplished at room temperature, so thermal stability of the analyte is usually not an issue. Eluting analytes are then ionized to produce spectra via electrospray ionization (ESI), atmospheric pressure chemical ionization (APCI), or atmospheric pressure photoionization (APPI).

However, LC-MS has not had the benefit of searchable libraries that contain reproducible spectra for several reasons. First, the pressure in the LC-MS ion source (no greater than $1 \mathrm{~atm}$ ) is higher relative to GC-MS because of the need to convert liquid to gas in the interface between the HPLC and the MS. Ions created at atmospheric pressure undergo ion-molecule collisions which alter the ion distribution depending on their residence time in the source and other factors. On the other hand, electron impact (EI) ionization that is typical of GC-MS systems operates at low gas pressure, which prevents ion-molecule collisions regardless of the ion source 
design. The fragmentation process is reproducible due to standard tuning criteria and the use of a standard $70 \mathrm{eV}$. There are many treatises written on the mechanisms that produce ions in EI ionization [3].

In atmospheric ionization sources (ESI, APCI, or APPI), multiple ion-molecule collisions remove energy from precursor ions, which then lack sufficient internal energy to fragment. This "soft ionization" generally provides mass spectra lacking product ions. A product ion due to loss of a water or carbon dioxide molecule can appear from some compounds. In addition to the precursor ion, adduct ions are often observed depending on the ionization environment due to the use of solvents and modifiers to optimize chromatography and sensitivity. These simple spectra, while they are indicative of the molecular weight, do not present the diagnostic power of the EI ionization spectra with its rich fragmentation pattern. A spectrum with a precursor ion and a few adduct ions is certainly not unique to a certain compound. Therefore, a library of such spectra would provide little discrimination among analytes.

To provide multiple product ions from analytes, the energy of collisions must be increased sufficiently to break bonds within the precursor ion. Single MS-stage instruments can use in-source collision-induced dissociation (CID), but the presence of various solvent, additive, and contaminant molecules can cause variation in the product ion spectra, and not all ions observed may originate from the analyte. Instruments, such as triple quadrupole mass spectrometers and ion traps, can focus the ion of interest and energize this species to effect further fragmentation free of extraneous ions. Both the ion trap and triple quadrupole mass spectrometers generate fragmentation by applying a voltage or energy to the ionized species and simultaneously add a collision gas to cause reactive collisions resulting in diagnostic ions. These product ions are related to the structure of the protonated or deprotonated molecule and could thus be used for diagnostic purposes. In principle, compilation of mass spectral libraries for each type of ionization and for both ion trap and triple quadrupole instruments should be feasible.

To provide reproducible product ion spectra for a library, voltage and collision gas pressures must be reproducible for individual instruments and for similar instruments that use the library. These requirements were not met by early ion traps and triple quadrupole mass spectrometers, and compilation of mass spectral libraries was not practical. However, an attempt was made to standardize conditions in triple quadrupole mass spectrometers. By using the kinetics of a well-defined reaction, Martinez [4] attempted to standardize conditions to generate reproducible spectra. Martinez's method was not valid for ion traps and little support was forthcoming from the analytical community for this attempt to standardize spectra. Consequently, the mass spectral library idea floundered.

Also desirable would be HPLC mass spectral libraries for singlestage quadrupole instruments, which are the workhorses for environmental analyses. Unfortunately, these instruments are not effective at generating product ions. An attempt was made to add a repeller to the ion sources of single quadrupole systems that could break apart protonated molecules [5], which were effective at generating product ions. However, this was not reproducible from instrument to instrument.

There have been direct efforts to generate EI ionization spectra under LC conditions. The particle beam LC-MS interface [6] removed most of the solvent in the interface before solvated ions entered the ion source and struck heated surfaces. The desolvated molecules were then ionized by $70-\mathrm{eV}$ electrons to provide EIsearchable mass spectra. This worked well for certain compounds [7], but was not universally adopted because of problems with thermal degradation and low volatility of compounds.

Another effort is the recent work by Granot and Amirav [8] to generate LC-MS spectra with EI ionization in supersonic molecular beams. This method shows some promise, but it is too early to predict its commercial application. Cappiello and Palma [9] interfaced a nanoscale $\mathrm{LC}$ to a direct electron ionization system to examine small to medium molecular weight molecules of different polarities. This technique shows some promise for those compounds that might have matrix problems when introduced through API interfaces.

Only recently have the electronics of mass spectrometers become stable enough that reproducible voltages and pressures provide reproducible CID spectra, at least on a single instrument. This stability is important in the collision region of a triple quadrupole mass spectrometer or the source region of a single quadrupole mass spectrometer through CID.

Therefore, it should be possible to collect spectra from an individual mass spectrometer and expect that these spectra will form a standardized library that the user can search during subsequent analyses. In fact, there should be two such libraries. The first would be generated from triple stage quadrupoles (LC-MS/MS), in which a single ion is focused, presumably the protonated molecule, in the first quadrupole and then sent into the second quadrupole or the collision cell, which contains an inert gas, such as argon, where the ion would undergo energetic collisions to produce product ions, which would be scanned in the third quadrupole and then detected. The other library from LC-MS spectra would be produced by some kind of device (repeller, cone, etc.) in the ion source that is effective at generating product ions. There would be no discrimination of the ions, so every ion in the source at the time of fragmentation would add to this spectrum. The first library described above would be "purer" than the latter because of the fact that interference ions could be present in the source as the voltages were applied to fragment the ion of interest.

Some attempts to compile searchable LC-MS and LC-MS/MS libraries with modern instruments have shown promise [10-15] while others encountered difficulties that precluded their use [16]. Encouraged by the success of Gergov et al. [11] in developing libraries for drugs, we attempted to create LC-MS and LC-MS/MS libraries for chemicals that could cause harm and disrupt distribution in a drinking water system. The ability to quickly and accurately identify a large number of organic compounds has become an important goal in this effort. LC-MS library technology is not only potentially useful for drinking water but also to identify or characterize agents that could be used in a terrorist incident, to monitor food safety, and to screen product quality.

LC-MS and LC-MS/MS libraries have been compiled for identification of chemicals that might pose a threat to drinking water. The Chicago Regional Laboratory (CRL) of the U.S. Environmental Protection Agency initially developed these libraries based on compounds that were potential threats to our nation's water supply. To validate the library protocol [17], other laboratories were recruited to verify that they could identify the chemicals in drinking water by comparing library mass spectra of standards with mass spectra from simulated unknowns obtained using the same solvents, methods, and instrument make as used by the CRL. In addition, the US EPA Office of Research and Development-Las Vegas Laboratory was recruited to test the library protocol with an instrument from a different manufacturer to determine if the library might have more general application.

\section{Experimental}

\subsection{Instrumentation}

The LC-MS Library System Protocol was developed using a Waters Corporation Quattro Premier ${ }^{\mathrm{TM}}$ triple quad (Milford, MA) with the ZSpray ${ }^{\mathrm{TM}}$ dual orthogonal sampling interface with Waters MassLynx $^{\mathrm{TM}} 4.0$ software. Other models used by the other labs 
during the validation were $\mathrm{ZQ}^{\mathrm{TM}}$ single quad and Quattro Micro ${ }^{\mathrm{TM}}$ triple quad. However, to test the applicability of the protocol across different makes, a Thermo Electron Corporation Finnigan TSQ Quantum Ultra $\mathrm{AM}^{\mathrm{TM}}$ triple quadrupole mass spectrometer (San Jose, CA) was tested in this study. MS and MS/MS library-searchable spectra were generated for comparison with the CRL libraries.

\subsection{Library development}

The first list of target compounds included in the library project was supplied by the Water Security Division of the US EPA Office of Water. These compounds of concern are toxic substances and are readily available. The target list was divided into two groups, base/neutral and acidic compounds. The first library protocol addressed the base/neutral compounds.

Most of the compounds in Table 1 were obtained as neat standards, generously provided by the US EPA Office of Pesticide Programs (OPP) National Pesticide Standards Repository. The others were purchased from Aldrich Chemical Company (Milwaukee, WI), Cambridge Isotope Laboratories (Andover, MA), and Cerilliant (Round Rock, TX). The standards were diluted using a 50:50 water:acetonitrile mixture to an approximate concentration of 400 ppm (parts per million).

To acquire library mass spectra, the CRL infused standard solutions into a ' $\mathrm{T}$ ' junction where they combined with mobile phase ( $5 \mathrm{mM}$ ammonium bicarbonate in 50:50 water:acetonitrile, $\mathrm{pH} 10$ ) before entering the mass spectrometer. Infusion was used to obtain optimal cone and collision energies for a compound to produce substantial fragmentation while maintaining at least 10\% abundance of the precursor ion. After these settings were obtained, LC-MS analysis (25 ng of material on column) was undertaken to acquire retention time data and to verify that the cone and collision energies during infusion provided similar fragmentation when the standard eluted from the column. The amount of material injected was used to make sure that the concentration levels provided enough ion statistics to provide quality spectra for identification with different library searching techniques.

For MS scanning (single quadrupole), the electrospray source conditions were as follows: capillary voltage: $3.5 \mathrm{kV}$; extractor: $2 \mathrm{~V}$; RF lens voltage: $0.2 \mathrm{~V}$; source temperature: $120^{\circ} \mathrm{C}$; desolvation temperature: $300^{\circ} \mathrm{C}$; desolvation gas flow: $500 \mathrm{Lh}^{-1}$; cone gas flow: $50 \mathrm{~L} \mathrm{~h}^{-1}$. The analyzer section was maintained as follows: entrance: $50 \mathrm{~V}$; exit: $50 \mathrm{~V}$; collision: $2 \mathrm{~V}$; multiplier: $650 \mathrm{~V}$. These were the optimal settings used at the CRL, but optimal settings may vary slightly from instrument to instrument. The optimal cone voltage was different for each compound; these values were tabulated (for MS and MS/MS) and are listed in Table 1 together with collision energies for each compound.

For MS/MS scanning (triple quadrupole), the electrospray source conditions were the same as for the MS scanning mode. The analyzer settings for the MS/MS scanning mode were as follows: entrance: $-1 \mathrm{~V}$; exit: $2 \mathrm{~V}$; collision: variable (see Table 1 ); multiplier: $650 \mathrm{~V}$.

The solvent gradient under which MS and MS/MS data were recorded was as follows: 95:5 $\left(\mathrm{H}_{2} \mathrm{O}: 100 \mathrm{mM} \mathrm{NH}_{4} \mathrm{HCO}_{3}, \mathrm{pH} 10\right)$ at time $=0$; hold for $2 \mathrm{~min}$; 95:5 (acetonitrile: $100 \mathrm{mM} \mathrm{NH}_{4} \mathrm{HCO}_{3}$ ) at time $=20.0 \mathrm{~min}$; hold for $2 \mathrm{~min}$; back to original conditions at time $=30.0 \mathrm{~min}$. The flow rate was $0.3 \mathrm{~mL} \mathrm{~min}^{-1}$. The column temperature was $30^{\circ} \mathrm{C}$ and the sample compartment was held at $15^{\circ} \mathrm{C}$.

The diagnostic precursor and product ions with relative abundances exceeding 5\% are listed in Table 1 . They represent spectra taken both under source CID (MS) and MS/MS conditions using the collision cell.

The instruments were tuned and calibrated according to the procedures given by the manufacturer. The initial protocol followed by the volunteer labs is given in the following sections.

\subsection{Tentative identification of an unknown}

\subsubsection{LC conditions and settings}

The LC conditions were set to screen water samples and were not optimized for chromatographic separation. The Waters Alliance ${ }^{\circledR}$ 2695 HPLC with an XBridge ${ }^{\mathrm{TM}} \mathrm{C} 18,2.1 \mathrm{~mm} \times 150-\mathrm{mm}$ column packed with 3.5- $\mu \mathrm{m}$ diameter particles, was used during the study. Any column capable of performing at high $\mathrm{pH}$ with adequate separation of these analytes may be used. The library protocol was not based on retention time of the analytes but on matching of spectra. The injection volume was $100 \mu \mathrm{L}$ of a filtered water sample if possible. The elution gradient and other conditions were described earlier.

\subsubsection{MS method file conditions and settings}

To acquire MS and MS/MS spectra, the mass spectrometer was tuned using the conditions specified earlier (see Section 2.2). The MS method file, made up of one or more individual MS scanning functions, was created to detect compounds of interest at specific retention times and cone voltage settings. For example, a cone voltage of $35 \mathrm{~V}$ is the optimal value for aldicarb sulfone, buprofezin, carbofuran, and three other compounds in Table 1 to acquire product ion mass spectra most similar to those in the library, while a cone voltage of $75 \mathrm{~V}$ is optimal for 2-aminobenzimidazole, cyprodinil, and thiabendazole. The combination of several such MS scanning functions, each with a different cone voltage, is best suited to screen for multiple compounds in a sample. This screening approach is used to maximize the number of compounds screened simultaneously.

To ensure mass spectra were acquired for water samples at the optimal or nearly optimal cone voltage for each compound in the library, the cone voltage was cycled through six values: $15,30,45$, 60,75 , and $90 \mathrm{~V}$ during acquisition. A 0.3-s scan was acquired for each voltage separated by a $0.1-\mathrm{s}$ interscan delay. The total cycle time was $2.4 \mathrm{~s}$ and HPLC chromatographic peak widths were typically $20-40 \mathrm{~s}$.

With in-source CID, co-eluting compounds can yield composite mass spectra containing product ions from multiple precursor ions, and good library matches are not likely. MS/MS is then necessary to isolate individual precursor ions before product ions are produced by CID to provide clean product ion spectra. Library-matchable product-ion spectra are then provided by the enhanced sensitivity and selectivity of MS/MS. For each unknown, MS/MS scanning methods require user input of the optimal cone voltage, collision energy, and precursor ion $m / z$ such as shown in Table 1 into a menu.

Similar retention times for a tentatively identified compound and the standard provide an orthogonal measure to strengthen tentative identifications made using the library.

\section{Results and discussion}

\subsection{Library searching}

After full scan spectra at various voltages have been recorded for each compound, these spectra were searched against the MS library as described by the Masslynx ${ }^{\mathrm{TM}}$ or NIST library search manual. When $>70 \%$ probability scores were obtained or when the operator thought a match was possible, the cone voltages from the library were compared with those for the acquired product ion spectra, and a tentative identification was made when they were consistent. The evidence for a somewhat doubtful, tentative identification of a compound could be enhanced by acquiring product ion spectra at the optimal cone voltage (and collision energy for MS/MS) for the compound from Table 1 to provide the strongest mass spectral evidence for the tentative identification. If the product ion spectrum is a match in the MS/MS library 
Table 1

Library compounds.

\begin{tabular}{|c|c|c|c|c|c|c|}
\hline Compound & CAS number & $\begin{array}{l}\text { Nominal mass } \\
(\mathrm{g} / \mathrm{mol})\end{array}$ & Cone $\mathrm{MS}^{\mathrm{a}}(\mathrm{V})$ & Cone MS/MS (V) & Collision MS/MS (eV) & $\begin{array}{l}\text { Precursor }>\text { MS/MS product ions } \\
\text { ( } m / z \text { units })\end{array}$ \\
\hline 2-Aminobenzimidazole & $934-32-7$ & 133 & 75 & 48 & 32 & $134>92,80$ \\
\hline 3-Hydroxy carbofuran & $16655-82-6$ & 237 & 40 & 30 & 9 & $220>163,135$ \\
\hline Acetamipirid & $135410-20-7$ & 222 & 46 & 25 & 14 & $223>126$ \\
\hline Acetochlor & $34256-82-1$ & 269 & 32 & 28 & 11 & $270>224,148$ \\
\hline Acibenzolar-s-methyl ${ }^{\mathrm{b}}$ & $135158-54-2$ & 210 & 60 & 37 & 23 & $211>168,136,91$ \\
\hline Aconitine & $302-27-2$ & 645 & 88 & 60 & 43 & $646>586,105$ \\
\hline Alachlor & $15972-60-8$ & 269 & 34 & 22 & 13 & $270>238,162$ \\
\hline Alanine $^{\mathrm{b}}$ & $56-41-7$ & 89 & 32 & 19 & 12 & $90>44$ \\
\hline Aldicarb & $116-06-3$ & 190 & 15 & 10 & 4 & $208>191,116$ \\
\hline Aldicarb sulfone & $1646-88-4$ & 222 & 35 & 25 & 8 & $223>166,148,76$ \\
\hline Aldicarb sulfoxide & $1646-87-3$ & 206 & 25 & 20 & 5 & $207>132,89$ \\
\hline Allethrin & $584-79-2$ & 302 & 34 & 20 & 9 & $303>151,135$ \\
\hline Ametryn & $834-12-8$ & 227 & 58 & 35 & 20 & $228>186,96$ \\
\hline Amitraz & $33089-61-1$ & 293 & 34 & 22 & 11 & $294>253,163$ \\
\hline ANTU & $86-88-4$ & 202 & 46 & 27 & 15 & $203>186,144$ \\
\hline Atrazine & $1912-24-9$ & 215 & 55 & 38 & 19 & $216>174,96,79$ \\
\hline Atropine & $51-55-8$ & 289 & 58 & 40 & 23 & $290>124,93$ \\
\hline Azinphos-methyl & $86-50-0$ & 317 & 25 & 18 & 6 & $318>261,160$ \\
\hline Azoxystrobin & $131860-33-8$ & 403 & 35 & 25 & 11 & $404>372$ \\
\hline Bentazon $^{\mathrm{b}}$ & 25057-89-0 & 240 & -55 & -35 & -24 & $239>197,132$ \\
\hline Bromoxynil $^{\mathrm{c}}$ & $1689-84-5$ & 275 & -53 & & & $276>79,81,185,274,123$ \\
\hline Buprofezin & 69327-76-0 & 305 & 35 & 22 & 13 & $306>201,116$ \\
\hline Butylate & $2008-41-5$ & 217 & 49 & 24 & 16 & $218>190,162,156,100,89$ \\
\hline Carbaryl & $63-25-2$ & 201 & 25 & 20 & 5 & $202>145$ \\
\hline Carbendazim & $10605-21-7$ & 191 & 40 & 30 & 15 & $192>160$ \\
\hline Carbofuran & $1563-66-2$ & 221 & 35 & 25 & 11 & $222>165,123$ \\
\hline Chloramben $^{\mathrm{b}}$ & $133-90-4$ & 205 & -31 & -20 & -8 & $204>160$ \\
\hline Chlorimuron-ethyl & $90982-32-4$ & 414 & 42 & 28 & 13 & $415>369,213,186$ \\
\hline Chlorobenzilate $^{\mathrm{b}, \mathrm{c}}$ & $510-15-6$ & 324 & -22 & & & $323>295,249$ \\
\hline Chlorsulfuron & $64902-72-3$ & 357 & 38 & 29 & 13 & $358>167,141$ \\
\hline Clethodim & $99129-21-2$ & 359 & 42 & 23 & 14 & $360>268,164$ \\
\hline Clodinafop-propargyl $^{\mathrm{c}}$ & $105512-06-9$ & 349 & 46 & & & $350>266,268,91,238,269$ \\
\hline Clomazone & $81777-89-1$ & 239 & 46 & 26 & 14 & $240>125,128$ \\
\hline Colchicine & $64-86-8$ & 399 & 72 & 41 & 29 & $400>358,310$ \\
\hline Cotinine & $486-56-6$ & 176 & 54 & 35 & 20 & $177>146,98,80$ \\
\hline Coumarin $^{\mathrm{b}}$ & $91-64-5$ & 146 & 55 & 35 & 20 & $147>103,91$ \\
\hline Cyanazine & $21725-46-2$ & 240 & 55 & 36 & 21 & $241>214,104,96$ \\
\hline Cyclanilide & $113136-77-9$ & 273 & -38 & -24 & -13 & $272>228,192,160$ \\
\hline Cycloheximide & $66-81-9$ & 281 & 45 & 30 & 16 & $282>264,246$ \\
\hline Cyprodinil & $121552-61-2$ & 225 & 75 & 48 & 28 & $226>210,108,93$ \\
\hline Cyromazine & $66215-27-8$ & 166 & 58 & 34 & 21 & $167>125,85$ \\
\hline Daminozide & $1596-84-5$ & 160 & 32 & 20 & 11 & $161>143,115,101$ \\
\hline $\mathrm{DDVP}^{\mathrm{b}}$ & $62-73-7$ & 220 & 44 & 32 & 15 & $221>145,127,109$ \\
\hline Desethyl atrazine & $19988-24-0$ & 169 & 48 & 32 & 16 & $170>128,86$ \\
\hline Desisopropyl atrazine & $1007-28-9$ & 173 & 57 & 32 & 22 & $174>132,104,96$ \\
\hline Diazinon & $333-41-5$ & 304 & 50 & 30 & 18 & $305>169,153$ \\
\hline Dicrotophos & $141-66-2$ & 237 & 35 & 25 & 9 & $238>193,112$ \\
\hline Digitoxin & $71-63-6$ & 764.4 & 31 & 22 & 9 & $783>748,636$ \\
\hline Digoxin $^{\mathrm{b}}$ & $20830-75-5$ & 780.4 & 33 & 22 & 10 & $782>652,97$ \\
\hline Diphacinone & $82-66-6$ & 340 & 45 & 30 & 14 & $341>323,263,235$ \\
\hline Diuron & $330-54-1$ & 232 & 40 & 30 & 14 & $233>72$ \\
\hline Dodine $^{b}$ & $2439-10-3$ & 287 & 67 & 40 & 23 & $228>186,85,71$ \\
\hline Emetine, $\mathrm{HCl}^{\mathrm{b}}$ & $483-18-1$ & 480 & 140 & 55 & 37 & $481>436,246,165$ \\
\hline EPTC & $759-94-4$ & 189 & 40 & 22 & 12 & $190>162,128,89,86$ \\
\hline Ethiofencarb & $56729-20-5$ & 225 & 25 & 18 & 7 & $226>169,164,107$ \\
\hline Ethion $^{\mathrm{b}}$ & $563-12-2$ & 384 & 30 & 20 & 8 & $385>215,199$ \\
\hline Ethoprophos & $13194-48-4$ & 242 & 42 & 27 & 13 & $243>215,173,131$ \\
\hline Fenitrothion ${ }^{\mathrm{b}, \mathrm{c}}$ & $122-14-5$ & 277 & & 32 & 17 & $278>246,125$ \\
\hline Fensulfothion & $115-90-2$ & 308 & 50 & 35 & 18 & $309>281,253,157$ \\
\hline Fenthion $^{\mathrm{b}}$ & $55-38-9$ & 278 & 55 & 30 & 16 & $279>247,169$ \\
\hline Formothion & $2540-82-1$ & 257 & 34 & 25 & 14 & $279>116,88,118,231,145$ \\
\hline Heroin & $561-27-3$ & 369 & 97 & 44 & 36 & $370>328,165$ \\
\hline Hexazinone & $51235-04-2$ & 252 & 38 & 28 & 13 & $253>171,85$ \\
\hline Imazalil & $35554-44-0$ & 296 & 55 & 35 & 21 & $297>255,159,109$ \\
\hline Imazamethabenz-methyl & $81405-85-8$ & 288 & 52 & 33 & 19 & $289>257,229,86$ \\
\hline Imazaquin & $81335-37-7$ & 311 & 60 & 36 & 24 & $312>270,267,252,199,86$ \\
\hline Imazethapyr & $81335-77-5$ & 289 & 58 & 35 & 23 & $290>248,245,230,177,86$ \\
\hline Imidacloprid & $13826-41-3$ & 255 & 40 & 29 & 14 & $256>209,175,84$ \\
\hline Isofenphos & 25311-71-1 & 345 & 18 & 10 & 4 & $346>287,245$ \\
\hline Isoxaflutole & $141112-29-0$ & 359 & 41 & 30 & 11 & $360>251$ \\
\hline Kresoxim-methyl & $143390-89-0$ & 313 & 30 & 20 & 7 & $314>282,267,206,116$ \\
\hline LAMPA & $40158-98-3$ & 323 & 60 & 34 & 25 & $324>281,223$ \\
\hline LSD & $50-37-3$ & 323 & 59 & 34 & 24 & $324>281,223$ \\
\hline Malathion & $121-75-5$ & 330 & 30 & 22 & 8 & $331>285,127$ \\
\hline Mesotrione & $104206-82-8$ & 339 & -29 & -16 & -8 & $338>291$ \\
\hline
\end{tabular}


Table 1 (Continued)

\begin{tabular}{|c|c|c|c|c|c|c|}
\hline Compound & CAS number & $\begin{array}{l}\text { Nominal mass } \\
(\mathrm{g} / \mathrm{mol})\end{array}$ & Cone $\mathrm{MS}^{\mathrm{a}}(\mathrm{V})$ & Cone MS/MS (V) & Collision MS/MS (eV) & $\begin{array}{l}\text { Precursor }>\text { MS/MS product ions } \\
\text { ( } m / z \text { units })\end{array}$ \\
\hline Metalaxyl & 57837-19-1 & 279 & 40 & 28 & 13 & $280>248,220,192$ \\
\hline Methamidophos & $10265-92-6$ & 141 & 50 & 35 & 18 & $143>125,113,95$ \\
\hline Methiocarb & $2032-65-7$ & 225 & 30 & 22 & 8 & $226>169,121$ \\
\hline Methomyl & $16752-77-5$ & 162 & 22 & 16 & 6 & $163>122,106,88$ \\
\hline Methoprene & 40596-69-8 & 310 & 22 & 15 & 6 & $311>279,237,219,191$ \\
\hline Metolachlor & $51218-45-2$ & 283 & 36 & 22 & 12 & $284>252$ \\
\hline Metsulfuron-methyl & $74223-64-6$ & 381 & 35 & 23 & 11 & $382>167,141$ \\
\hline Mevinphos & $7786-34-7$ & 224 & 27 & 20 & 7 & $225>193,127,99$ \\
\hline Molinate & $2212-67-1$ & 187 & 37 & 26 & 13 & $188>126,98,83$ \\
\hline Monocrotophos & $6923-22-4$ & 223 & 30 & 21 & 8 & $224>193,98$ \\
\hline Naled $^{\mathrm{b}}$ & $300-76-5$ & 378 & 24 & 23 & 8 & $379>127$ \\
\hline Napropamide & $15299-99-7$ & 271 & 45 & 28 & 14 & $272>199,171,129,74$ \\
\hline Naptalam & $132-66-1$ & 291 & -38 & -23 & -12 & $290>246$ \\
\hline Nicotine & $54-11-5$ & 162 & 50 & 35 & 18 & $163>132,130,117,106$ \\
\hline Oxamyl & $23135-22-0$ & 219 & 20 & 14 & 6 & $237>220,90,72$ \\
\hline Permethrin ${ }^{\mathrm{b}}$ & $52645-53-1$ & 390 & 32 & 24 & 8 & $408>355,183$ \\
\hline Phorate $^{\mathrm{b}}$ & $298-02-2$ & 260 & 20 & 18 & 6 & $261>75$ \\
\hline Phosalone $^{\mathrm{b}}$ & $2310-17-0$ & 367 & 36 & 25 & 9 & $368>322,182$ \\
\hline Phosmet $^{\mathrm{b}}$ & $732-11-6$ & 317 & 30 & 20 & 7 & $318>160$ \\
\hline Pirimicarb & $23103-98-2$ & 238 & 42 & 28 & 14 & $239>182,72$ \\
\hline Pirimiphos-methyl & 29232-93-7 & 305 & 60 & 42 & 24 & $306>164,136,108,95$ \\
\hline Prometon & $1610-18-0$ & 225 & 56 & 35 & 20 & $226>184,142$ \\
\hline Prometryn & $7287-19-6$ & 241 & 56 & 36 & 21 & $242>200,158$ \\
\hline Propachlor & 1918-16-7 & 211 & 41 & 26 & 14 & $212>170,152$ \\
\hline Propamocarb & $24579-73-5$ & 188 & 39 & 26 & 14 & $189>144,102$ \\
\hline Propoxur & $114-26-1$ & 209 & 28 & 20 & 7 & $210>168,153,111$ \\
\hline Prosulfuron & $94125-34-5$ & 419 & 45 & 30 & 15 & $420>167,141$ \\
\hline Pyridaben & $96489-71-3$ & 364 & 34 & 25 & 11 & $365>309,147$ \\
\hline Pyridaphenthion & $119-12-0$ & 340 & 50 & 37 & 18 & $341>313,205,189$ \\
\hline Quinine & $56-54-2$ & 324 & 73 & 38 & 28 & $325>160,81$ \\
\hline Resmethrin ${ }^{\mathrm{b}}$ & $10453-86-8$ & 338 & 42 & 25 & 15 & $339>321,293,171,143,121,91$ \\
\hline Sethoxydim & $74051-80-2$ & 327 & 45 & 25 & 15 & $328>282,220,180,178$ \\
\hline Simazine & $122-34-9$ & 201 & 55 & 40 & 20 & $202>174,132,124,104,96$ \\
\hline Simetryn & $1014-70-6$ & 213 & 60 & 40 & 21 & $214>186,144,124,96$ \\
\hline Spiroxamine & $118134-30-8$ & 297 & 51 & 32 & 17 & $298>144,100$ \\
\hline Strychnine & $57-24-9$ & 334 & 95 & 66 & 44 & $335>184,156,144,129$ \\
\hline Tebuconazole & $107534-96-3$ & 307 & 53 & 34 & 20 & $308>165,151,125$ \\
\hline Tebufenpyrad & $119168-77-3$ & 333 & 70 & 48 & 26 & $334>171,145,117$ \\
\hline Temephos & $3383-96-8$ & 466 & 62 & 35 & 22 & $467>419,405,357,249,155,125$ \\
\hline Terbumeton & $33693-04-8$ & 225 & 45 & 33 & 16 & $226>170,114$ \\
\hline Terbuthylazine & $5915-41-3$ & 229 & 45 & 31 & 14 & $230>174$ \\
\hline Thiabendazole & $148-79-8$ & 201 & 75 & 44 & 29 & $202>175,131,92$ \\
\hline Thiamethoxam & $153719-23-4$ & 291 & 33 & 20 & 10 & $292,246,211,210,132$ \\
\hline Thifensufuron-methyl & $79277-27-3$ & 387 & 38 & 26 & 11 & $388>167,141$ \\
\hline Thiram & $137-26-8$ & 240 & 21 & 12 & 7 & $241>196,120,88$ \\
\hline Tralkoxydim & $87820-88-0$ & 329 & 44 & 25 & 15 & $330>284,164,138,122$ \\
\hline Triadimefon & $43121-43-3$ & 293 & 45 & 28 & 16 & $294>225,197$ \\
\hline Tri-allate $^{b}$ & $2303-17-5$ & 303 & 41 & 26 & 15 & $304>262,143,128,86$ \\
\hline Triasulfuron & $82097-50-5$ & 401 & 42 & 28 & 15 & $402>219,167,141$ \\
\hline Trichlorfon $^{\mathrm{b}}$ & $52-68-6$ & 256 & 39 & 26 & 12 & $257>221,127$ \\
\hline Trifloxystrobin ${ }^{\mathrm{b}}$ & $141517-21-7$ & 408 & 40 & 24 & 13 & $409>206,186,116$ \\
\hline Trinexapac-ethyl & $95266-40-3$ & 252 & 39 & 25 & 13 & $253>207,185,69$ \\
\hline Triticonazole & 131983-72-7 & 317 & 36 & 25 & 12 & $318>70$ \\
\hline Warfarin & $81-81-2$ & 308 & 42 & 25 & 13 & $309>251,163$ \\
\hline
\end{tabular}

a For full scan (single quadrupole) MS analysis, the collision energy was maintained at $2 \mathrm{eV}$ and the collision gas (argon) remained off.

b These compounds have not been verified in interlaboratory studies.

c Those compounds in this table that only have MS settings are in the MS library only; and those compounds that only have MS/MS settings are only in the MS/MS library.

there is a high probability that the unknown has been identified.

\subsection{Inter-laboratory verification of protocol and libraries}

Thirteen solutions containing a total of 129 organic compounds included in the CRL libraries were prepared and distributed by CRL to the six participating laboratories. Each unknown sample contained between 9 and 11 analytes. Each participating lab received 6 or 7 unknown solutions that they were required to characterize. The unknown solutions were mixed considering retention time so the compounds would not co-elute. The samples were allotted so that a total of three laboratories received each individual chemical. The concentration of each analyte was 20 times (at a minimum) the noise level found at CRL. The laboratories did not know what compounds were contained in the solutions they received. Each laboratory was required to identify the constituents in the solutions they received using LC-MS Library System Protocol Version 1.2 created by CRL [17].

Identification of an analyte was required by at least two out of three laboratories that received it for the library spectra to be considered verified. Any less than two correct identifications would require further work on the spectra in the library or consultation with the participating labs depending on possible reasons for the misidentification. Compounds that were not correctly identified would be listed as not verified in the library until they were satisfactorily identified in blind samples by at least two out of three laboratories. 
Table 2

Results of inter-laboratory verification.

\begin{tabular}{|c|c|c|c|}
\hline Legend reason codes & \multicolumn{3}{|l|}{ Definitions } \\
\hline $\begin{array}{l}\text { A } \\
\text { B } \\
\text { C } \\
\text { D } \\
\text { F }\end{array}$ & $\begin{array}{l}\text { Found by participat } \\
\text { Found at CRL, overs } \\
\text { Found at CRL, mask } \\
\text { Not found at CRL, p } \\
\text { Not found at CRL, b }\end{array}$ & $\begin{array}{l}\text { g lab } \\
\text { ht by participatir } \\
\text { l by high backgro } \\
\text { ticipating lab did } \\
\text { kground noise le }\end{array}$ & $\begin{array}{l}\mathrm{ab} \\
\mathrm{d} \text { noise level } \\
\text { t follow protocol } \\
\text { high }\end{array}$ \\
\hline Compound & $\begin{array}{l}\text { Lab result one } \\
\text { reason }\end{array}$ & $\begin{array}{l}\text { Lab result two } \\
\text { reason }\end{array}$ & $\begin{array}{l}\text { Lab result three } \\
\text { reason }\end{array}$ \\
\hline Acibenzolar-s-methyl & $\mathrm{C}$ & $\mathrm{F}$ & A \\
\hline Bentazon & $\begin{array}{l}\text { A (not confirmed } \\
\text { by MS/MS) }\end{array}$ & A & C \\
\hline Chloramben & $\mathrm{C}$ & $\mathrm{F}$ & $\mathrm{C}$ \\
\hline Chlorobenzilate & B & A & $\mathrm{F}$ \\
\hline Coumarin & B & A & $\mathrm{F}$ \\
\hline DDVP & $\mathrm{F}$ & A & $\mathrm{F}$ \\
\hline Digoxin & B & $\mathrm{C}$ & A \\
\hline Dodine & $\mathrm{F}$ & A & $\mathrm{F}$ \\
\hline Emetin, $\mathrm{HCl}$ & A & $\mathrm{F}$ & B \\
\hline Ethion & $\mathrm{C}$ & A & $\mathrm{F}$ \\
\hline Fenthion & $\mathrm{F}$ & $\mathrm{F}$ & $\mathrm{C}$ \\
\hline Naled & C & $\mathrm{F}$ & A \\
\hline Permethrin & A & B & $\mathrm{F}$ \\
\hline Phorate & $\mathrm{F}$ & $\mathrm{F}$ & A \\
\hline Phosmet & A & B & $\mathrm{F}$ \\
\hline Trifloxystrobin & A & $\mathrm{D}$ & B \\
\hline Alanine & $\mathrm{F}$ & C & $\mathrm{C}$ \\
\hline Fenitrothion & $\mathrm{F}$ & $\mathrm{F}$ & $\mathrm{F}$ \\
\hline Phosalone & $\mathrm{C}$ & $\mathrm{C}$ & $\mathrm{F}$ \\
\hline Resmethrin & $\mathrm{F}$ & $\mathrm{F}$ & $\mathrm{F}$ \\
\hline Tri-allate & C & $\mathrm{F}$ & $\mathrm{F}$ \\
\hline Trichlorfon & $\mathrm{F}$ & $\mathrm{F}$ & $\mathrm{F}$ \\
\hline
\end{tabular}

The results using Waters instrumentation verified 107 out of 129 compounds contained in the library as shown in Table 1 . The compounds with the letter " $b$ " were not verified through the interlaboratory process. The reasons are discussed here and tabulated in Table 2.

LAMPA, which is iso-LSD, has the same mass spectrum as LSD and cannot be distinguished by this protocol. LAMPA is not psychoactive, but like LSD, it is classified as a Schedule I drug under the Controlled Substance Act of 1970. Because LSD is prepared from ergot alkaloids with isomeric configuration at the $C-8$ position, both LSD and LAMPA are present in most illicit drug preparations. An LC-MS library cannot distinguish between LSD and LAMPA since they are sterioisomers. Therefore, if LAMPA or LSD is identified in a sample, it was verified to be reported as LAMPA/LSD.

Dicrotophos, used as a spiking compound, degraded to monocrotophos and was identified by two participating labs as monocrotophos in the sample.

Fenitrothion was identified by MS/MS only. The compound provided insufficient ion abundance in MS full scans to be tentatively identified in the MS single quadrupole portion of the protocol.

Bromoxynil, chlorobenzilate, clodinafop-propargyl, and formothion were tentatively identified by MS only. No MS/MS spectra are in the library for these compounds due to poor MS/MS sensitivity.

The reasons the 22 compounds were not verified, after CRL reviewed all the data received from the participating labs, are provided in Table 2. Contributing factors may be poor sensitivity due to poor chromatography or matrix interferences caused by elevated chromatograph baselines. It is also believed that some compounds may have decomposed in the water samples before being analyzed by the participating labs. Bentazon was found by two labs, but one lab was not able to confirm its presence by MS/MS. There were no false positives reported by the participating laboratories.

\subsection{Library protocol modifications and library searching for the Thermo Finnigan instrument}

A Thermo Finnigan instrument was used to compile similar LC-MS and LC-MS/MS libraries. The instrument was tuned according to the manufacturer's specifications and for maximum sensitivity before spectral acquisition. Other than this initial optimization process, similar procedures as noted above were followed to develop a standardized library that could be compared with the Waters/CRL libraries. Infusing each compound into the ESI source allowed for maximizing the signal by tuning the gas flows and voltages, while observing the $[\mathrm{M}+\mathrm{H}]^{+}$or $[\mathrm{M}-\mathrm{H}]^{-}$ion. As with the Waters instrument, each standard was infused into a ' $T$ ' junction, where it combined with the mobile phase before entering the mass spectrometer. The electrospray source conditions for both MS and MS/MS scanning were as follows: spray voltage, $4000 \mathrm{~V}$; sheath gas pressure, 40 units; auxiliary gas pressure, 10 units; and capillary temperature, $250^{\circ} \mathrm{C}$. During this process, source CID voltages (for LC-MS spectra) and collision energies (for LC-MS/MS spectra) were manipulated for each compound to generate fragmentation while maintaining at least $10 \%$ abundance of the precursor ion. Once these settings were obtained, LC-MS analysis of $25 \mathrm{ng}$ of material on-column was performed to acquire retention time data and to verify that similar product ion spectra were obtained with the source CID voltages and collision energies used during infusion. The collision gas (argon) was kept at 1.5 mTorr and the collision energy was increased to reduce the precursor ion to $10 \%$ of the resulting base peak.

A subset of the 129 unknown compounds sent to the US EPA Office of Research and Development Laboratory in Las Vegas was analyzed for independent confirmation on instrumentation from a manufacturer other than that used in the inter-laboratory study. MS spectra were acquired with a Thermo Finnigan TSQ Quantum Ultra $\mathrm{AM}^{\mathrm{TM}}$ triple quadrupole mass spectrometer at collision energies of $10,20,30,40,50,60$, and $76 \mathrm{~V}$ (maximum). Each spectrum at each voltage was examined to determine the highest probability match and the instrument provided excellent matches with the Waters/CRL LC-MS library.

The 67-compound subset of the unknown standards was then tested against this library. The probability indicated the confidence that the unknown spectrum matched that particular compound's spectrum in the CRL library. The matches demonstrated that the LC-MS libraries are transferable between the Waters and Thermo Finnigan instruments even though the ion ratios within spectra were often different between the instruments. Even so, the NIST search engine probability match factor was high and correctly identified the simulated unknowns as shown in Table 3. The MS cone/source CID voltages were compared between the voltage under which the Waters/CRL library was developed and the voltage that resulted in the greatest match factor using the Thermo Finnigan NIST search and are presented in Table 3.

Based on the NIST searching algorithm the probabilities of finding each simulated unknown in the Waters/CRL library was $96 \%$ or greater except for metsulfuron-methyl, monocrotophos, and phosmet, which had probabilites of 83,94 , and $90 \%$, respectively. Examples of these searches are given in Fig. 1 for propachlor and Fig. 2 for metsulfuron-methyl.

As can be seen, the algorithm ranks the occurrence of ions greater than the ion abundance. Since each spectrum is searched against the whole library, one can see from the search results in Fig. 1 that for propachlor, there is very little probability that the compound is anything other than propachlor; the next highest probability is $0.98 \%$ for terbumeton. The search results for metsulfuron-methyl are more tentative as the forward and reverse search results are poor, but the probability that the compound is metsulfuron-methyl is still at $83 \%$ with the next highest proba- 
Table 3

LC-MS library match probability of spectra acquired by the Thermo Finnigan instrument against the Waters/CRL LC-MS library.

\begin{tabular}{|c|c|c|c|}
\hline \multirow[t]{2}{*}{ Compound } & \multicolumn{2}{|c|}{ MS cone/source CID (V) } & \multirow[t]{2}{*}{ NIST probability } \\
\hline & $\begin{array}{l}\text { Waters/CRL } \\
\text { library }\end{array}$ & Thermo Finnigan & \\
\hline 2-Aminobenzimidazole & 75 & 60 & 97 \\
\hline 3-Hydroxy carbofuran & 40 & 50 & 99 \\
\hline Acetamipirid & 46 & 40 & 99 \\
\hline Acetochlor & 32 & 50 & 99 \\
\hline Alachlor & 34 & 50 & 98 \\
\hline Aldicarb & 15 & 20 & 99 \\
\hline Ametryn & 58 & 60 & 99 \\
\hline Amitraz & 34 & 40 & 97 \\
\hline Atropine & 58 & 60 & 96 \\
\hline Azinphos-methyl & 25 & 40 & 99 \\
\hline Azoxystrobin & 35 & 50 & 99 \\
\hline Buprofezin & 35 & 40 & 99 \\
\hline Carbaryl & 25 & 40 & 99 \\
\hline Carbofuran & 35 & 40 & 99 \\
\hline Clodinafop-propargyl & 46 & 50 & 98 \\
\hline Clomazone & 46 & 60 & 99 \\
\hline Colchicine & 72 & 76 & 97 \\
\hline Cyanazine & 55 & 76 & 98 \\
\hline Cycloheximide & 45 & 60 & 99 \\
\hline Cyprodinil & 75 & 60 & 99 \\
\hline Diazinon & 50 & 40 & 99 \\
\hline Dicrotophos & 35 & 40 & 99 \\
\hline Ethiofencarb & 25 & 40 & 99 \\
\hline Ethoprophos & 42 & 40 & 99 \\
\hline Fensulfothion & 50 & 76 & 98 \\
\hline Hexazinone & 38 & 60 & 98 \\
\hline Imazalil & 55 & 50 & 98 \\
\hline Imazamethabenz-methyl & 52 & 60 & 99 \\
\hline Imidacloprid & 40 & 50 & 99 \\
\hline Isofenphos & 18 & 20 & 99 \\
\hline Kresoxim-methyl & 30 & 20 & 99 \\
\hline Malathion & 30 & 30 & 98 \\
\hline Methiocarb & 30 & 30 & 99 \\
\hline Methomyl & 22 & 40 & 99 \\
\hline Metolachlor & 36 & 40 & 99 \\
\hline Metsulfuron-methyl & 35 & 30 & 83 \\
\hline Mevinphos & 27 & 30 & 98 \\
\hline Monocrotophos & 30 & 40 & 94 \\
\hline Naled & 24 & 30 & 98 \\
\hline Napropamide & 45 & 60 & 99 \\
\hline Nicotine & 50 & 40 & 98 \\
\hline Oxamyl & 20 & 30 & 97 \\
\hline Phosmet & 30 & 30 & 90 \\
\hline Pirimicarb & 42 & 40 & 98 \\
\hline Pirimiphos-methyl & 60 & 60 & 99 \\
\hline Prometon & 56 & 60 & 99 \\
\hline Prometryn & 56 & 60 & 99 \\
\hline Propachlor & 41 & 50 & 99 \\
\hline Propamocarb & 39 & 30 & 99 \\
\hline Propoxur & 28 & 50 & 99 \\
\hline Prosulfuron & 45 & 76 & 99 \\
\hline Pyridaben & 34 & 40 & 99 \\
\hline Pyridaphenthion & 50 & 60 & 98 \\
\hline Quinine & 73 & 60 & 96 \\
\hline Sethoxydim & 45 & 40 & 97 \\
\hline Simetryn & 60 & 50 & 99 \\
\hline Spiroxamine & 51 & 50 & 99 \\
\hline Tebuconazole & 53 & 50 & 98 \\
\hline Tebufenpyrad & 70 & 76 & 98 \\
\hline Temephos & 62 & 60 & 99 \\
\hline Terbumeton & 45 & 40 & 99 \\
\hline Thiamethoxam & 33 & 50 & 99 \\
\hline Triadimefon & 45 & 30 & 98 \\
\hline Triasulfuron & 42 & 50 & 98 \\
\hline Trichlorfon & 39 & 30 & 97 \\
\hline Trifloxystrobin & 40 & 40 & 99 \\
\hline Warfarin & 42 & 30 & 99 \\
\hline
\end{tabular}

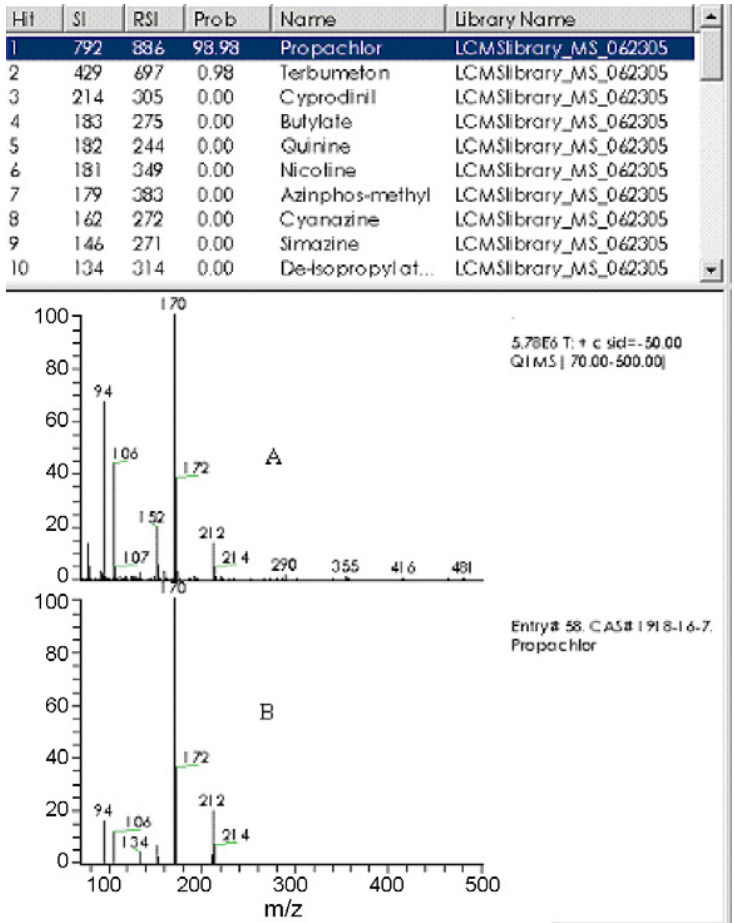

Fig. 1. LC-MS library search of propachlor acquired on a Thermo Finnigan instrument (A) compared to the library spectrum generated from a Waters instrument (B)

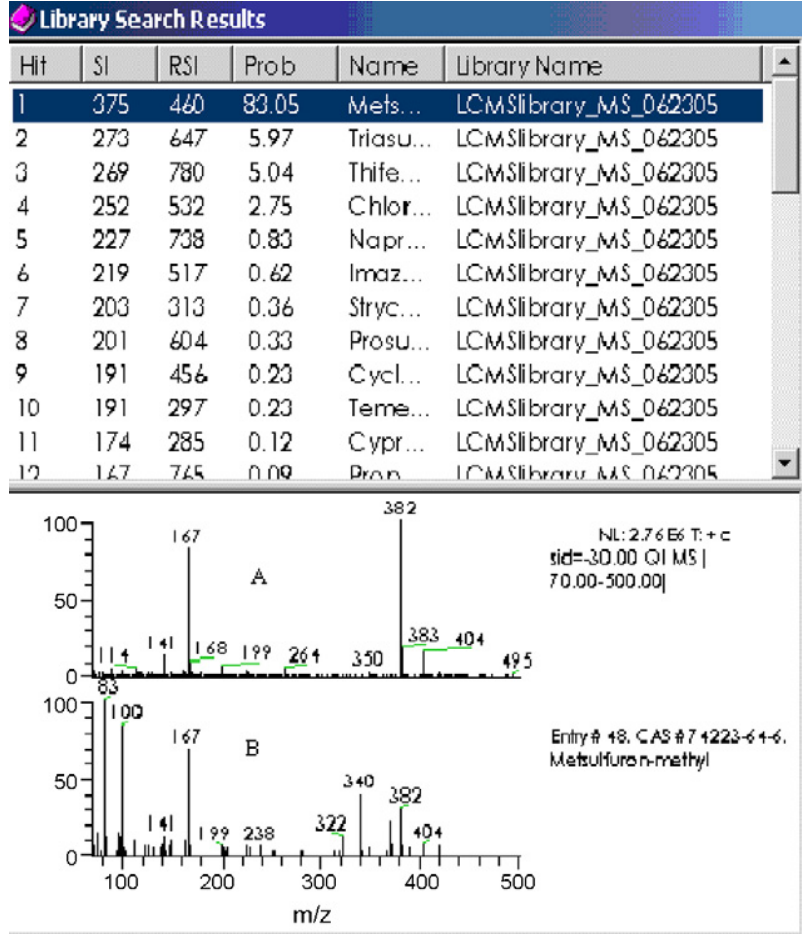

Fig. 2. LC-MS library search of metsulfuron-methyl acquired on a Thermo Finnigan instrument (A) compared to the library spectrum generated from a Waters instrument (B). 
bility at 6\%. On further review the Waters/CRL LC-MS library for metsulfuron-methyl most likely had interferences, which were not filtered out with the source CID LC-MS arrangement. Review of the Waters/CRL LC-MS/MS library (products of $\mathrm{m} / z$ 382) showed that ions at $m / z 83,100$, and 340 were all absent; consequently, these ions were attributed to co-eluting impurities with the metsulfuronmethyl.

\section{Conclusion}

The Waters/CRL LC-MS library protocol was verified through an inter-laboratory study that involved Federal, State, and private laboratories. The results demonstrated that the libraries are transferable between the same manufacturer's product line, and have applicability between manufacturers. The ion ratios within a mass spectrum were different between two manufacturers' instruments, but the same product ions were usually observed. Despite the ion ratio differences, the NIST search engine match probability was $96 \%$ or greater for all of the compounds except for three. This work will be extended for the analysis of real world samples and the development of more sensitive MS/MS methods to enable low level analysis of select analytes. Through a cooperative research and development agreement (CRADA) between Waters Corporation and the US EPA Region 5 CRL, the libraries and protocol can be obtained from U.S. EPA Region 5 CRL free of charge.

\section{Acknowledgements}

We would like to thank the following participants in the interlaboratory validation: Jeff Hardy, Indiana State Chemist; Julia Jiang, Minnesota Department of Public Health; Patricia Schermerhorn, Diane Rains, and Paul Golden, US EPA Office of Pesticide Programs; and Harold Johnson, Gordon Kearney, and Aisling O'Connor, Waters
Corporation. We would like to especially thank the US EPA Office of Pesticide Programs (OPP) National Pesticide Standards Repository for providing many of the standards and the US EPA Office of Water/Water Security Division and Office of Research and Development/National Homeland Security Research Center for financial support.

\section{References}

[1] EPA Method 624 Appendix A 40 CFR Part 136, US EPA, Washington, DC, 2008.

[2] NIST Standard Reference Database 1A, NIST/EPA/NIH Mass Spectral Library with Search Program: (Data Version: NIST 05, Software Version 2.0d), NIST, 2005.

[3] F.W. McLafferty, Interpretation of Mass Spectra, University Science Books, Mill Valley, 1980.

[4] R.I. Martinez, Journal of the American Society for Mass Spectrometry 1 (1990) 272.

[5] J. Yinon, T.L. Jones, L.D. Betowski, Rapid Communications in Mass Spectrometry 3 (1989) 38.

[6] R.C. Willoughby, R.F. Browner, Analytical Chemistry 56 (1984) 2626.

[7] L.D. Betowski, C.M. Pace, M.R. Roby, Journal of the American Society for Mass Spectrometry 3 (1992) 823.

[8] O. Granot, A. Amirav, International Journal of Mass Spectrometry 244 (2005) 15.

[9] A. Cappiello, P. Palma, Advances in LC-MS Instrumentation, Elsevier Science \& Technology Books, 2007.

[10] S. Dresen, J. Kempf, W. Weinmann, Forensic Science International 161 (2006) 86.

[11] M. Gergov, W. Weinmann, J. Meriluoto, J. Uusitalo, I. Ojanperä, Rapid Communications in Mass Spectrometry 18 (2004) 1039.

[12] P. Marquet, F. Saint-Marcoux, T.N. Gamble, J.C.Y. Leblanc, Journal of Chromatography B 789 (2003) 9.

[13] P. Marquet, N. Venisse, L.É.G. Lachâtre, Analusis 28 (2000) 925

[14] A. Schreiber, J. Efer, W. Engewald, Journal of Chromatography A 869 (2000) 411.

[15] W. Weinmann, A. Wiedemann, B. Eppinger, M. Renz, M. Svoboda, Journal of the American Society for Mass Spectrometry 10 (1999) 1028.

[16] M.J. Bogusz, R.-D. Maier, K.D. Kruger, K.S. Webb, J. Romeril, M.L. Miller, Journal of Chromatography A 844 (1999) 409.

[17] L. Zintek, J. Neukom, LC-MS-Library System Protocol Version 1. 2, US EPA, Region 5 Chicago Regional Laboratory, Chicago, 2006. 